\title{
Síndrome de Goldenhar e a educação inclusiva
}

\author{
Claus Dieter Stobäus* \\ Carla Rejane Crixel Fernandes**
}

Resumo

Discutimos elementos da Monografia de Conclusão de Curso de Fernandes com opiniões de seu orientador (Stobäus), centrando em interfaces com a Educação Especial/ Inclusiva, apontando elementos anatômico-funcionais da Síndrome, revisando dificuldades encontradas na inclusão desta criança na Rede Regular de Ensino, através de entrevista com sua mãe e sua professora.

Palavras-chave: Síndrome de Goldenhar; Educação Especial; Educação Inclusiva.

* Professor Doutor da Pontifícia Universidade Católica do Rio Grande do Sul, Porto Alegre, Rio Grande do Sul, Brasil.

** Especialista em Educação Inclusiva pela Pontifícia Universidade Católica do Rio Grande do Sul, Porto Alegre, Rio Grande do Sul, Brasil. 


\title{
Goldenhar Syndrome and full inclusion
}

\section{Abstract}

We discuss the information included in Fernandes' Monograph and opinions of his advisor (Stobäus), centered in interfaces with Special Education/Full Inclusion, pointing anatomic-functional elements of this Syndrome, reviewing difficulties encountered in full inclusion, by an interview with his mother and teacher.

Keywords: Goldenhar Syndrome; Special Education; Full Inclusion.

\section{Aspectos anatômico-funcionais}

Encontramos poucos autores que estudam esta malformação. Para Pinheiro, Araújo, Oliveira e Sampaio (apud PINTO, ARAÚJO, SOUSA e CHIARI, 2007, p. 142), "a Síndrome de Goldenhar é uma anomalia congênita rara, caracterizada por alterações oculares, auriculares e vertebrais, frequentemente associadas a outras malformações congênitas viscerais ou faciais", e (p. 142):

\begin{abstract}
Acredita-se que a Síndrome de Goldenhar faça parte de um quadro clínico mais complexo de anomalias de primeiro e segundo arcos branquiais, o qual é mais comumente conhecido como espectro óculo-aurículo-vertebral e é caracterizado pela presença adicional de dermóides epibulbares.
\end{abstract}

Pinheiro et al. (apud PINTO, FIGUEIREDO e GUARIENTI, 2004, p. 26) escrevem que "a incidência da Síndrome de Goldenhar situa-se entre l em 3.500 e l em 26.000 nascimentos", e que:

Em 1881, o primeiro caso foi descrito por Von Arit. A Síndrome foi caracterizada por Goldenhar (1952/1953), em detalhe, recebendo seu nome, em 1963. Gorlin et al., em 1963, sugerem o nome síndrome óculo-aurículo-vertebral (OAV), incluindo anomalias vertebrais como características dessa Síndrome.

Tasse et al. (apud PINTO, ARAÚJO, SOUSA e CHIARI, 2007, p. 142) dizem que a "incidência varia em uma faixa de 1 para 5.600 recém-nascidos. A relação entre meninos e meninas portadores da Síndrome é de aproximadamente 3:2. A freqüência em relação aos lados afetados (direito versus esquerdo) é de l:1".

Silva e Penido (apud PINTO, FIGUEIREDO e GUARIANTE, 2004, p. 26) destacam que "os principais defeitos encontrados nesse conjunto de malformações são devidos principalmente a erros de morfogênese do primeiro e segundo arcos branquiais, acompanhados em alguns casos de malformações das vértebras e/ou dos olhos". 
Smith (1985 p. 511) diz que "a etiologia é desconhecida. Afecção de caráter quase sempre esporádico. Calcula-se que a incidência em outros parentes de primeiro grau esteja em torno de $2 \%$, se bem que os parentes apresentem às vezes manifestações discretas desta afecção".

Segundo Mocelin, Capasso, Catam, Gasperin e Junior (1998, p. 77), "as manifestações são usualmente mais severas quando a herança é paterna, autossômica dominante, $[\ldots]$ evidências da heterogenicidade genética".

Estudos em modelos animais sugerem que a Síndrome de Goldenhar surge por uma disrupção vascular no embrião, entre o $35^{\circ}$ e $40^{\circ}$ dia de gestação. A disrupção impede a morfogênese correta das estruturas derivadas do primeiro e segundo arcos branquiais, resultando no quadro clínico presente ao nascimento.

p. 142):

Afirmam Pinheiro et al. (apud PINTO, ARAÚJO, SOUSA e CHIARI, 2007,

As causas mais comumente relatadas são: anormalidades cromossômicas, distúrbio na migração das células neurais, diabetes materna, fatores ambientais durante a gravidez e ingestão de drogas pela mãe, tais como: cocaína, talidomida, ácido retinóico e tamoxifen.

Conforme Sanvito (1997, p. 206):

O complexo sintomatológico, conhecido como síndrome de Goldenhar, tem como características essenciais: 1) nos olhos: dermóide epibulbar e/lipodermóide; 2) nas orelhas: apêndices dérmicos pré auriculares e fístulas cegas na região do pré-trago; 3) anomalias vertebrais: hemivértebra, fusão de vértebras cervicais. Outras manifestações embora menos constantes, podem ser encontradas no quadro clínico: assimetria craniana, bossa frontal, coloboma, microftamia, microcómea, catarata polar, atresia das narinas, hipoplasia mandibular, paralisia facial, implantação baixa dos cabelos, malformações cardíacas e das extremidades. Retardo mental moderado pode ocorrer em 10\% a $20 \%$ dos casos.

Quanto à evolução, Smith (1989, p. 511) escreve que:

A cirurgia plástica está definitivamente indicada. A maioria dos pacientes possuem inteligência normal. Os casos de oligofrenia acompanham-se geralmente de microftalmia. A acuidade auditiva deve ser examinada desde cedo.

Convém destacar que as limitações que podem ser manifestadas nesta Síndrome não podem ser ignoradas ao levarmos em conta seu processo educacional. Durante esse período, é importante lembrar de suas dificuldades, para minimizá-las, e que o professor utilize recursos adaptativos que estimulem todos os sentidos e des- 
pertem, no aluno, uma possibilidade de ampliar seus horizontes, em busca da superação de suas próprias limitações, lembrando sempre de que cada indivíduo é único, independente de sua deficiência ou dificuldade, com oportunidades para seu desenvolvimento.

\section{A chegada de uma criança especial}

Kortmann (apud STOBÄUS e MOSQUERA, 2006, p. 222) lembra que as pessoas constroem o sonho de constituir família, desejando a chegada de filhos com grandes expectativas idealizadas. Porém, às vezes esta etapa requer envolvimento maior quando trata-se de criança especial, então, para recepcioná-la, é preciso que se constitua uma 'família especial', pois "crescemos e resolvemos trocar os bonecos por um boneco(a) de verdade, porque sonhamos em construir famílias, sonhamos com nossos filhos de verdade".

Incertezas e questionamentos são inevitáveis quando pais deparam-se com filho que é diferente: por que comigo?, que eu fiz de errado?, que vai acontecer daqui pra frente? Há muitas vezes a negação inicial deste filho 'diferente', superada pela posterior aceitação, pois já existem recursos e apoio de equipes multiprofissionais especializadas.

Convém salientar que, inegavelmente, a família é a principal fonte de desenvolvimento de seu filho e seu papel é primordial e intransferível, porém uma equipe multiprofissional oportuniza-a descobrir como estimulá-la: fonoaudiólogos, psicólogos, terapeutas ocupacionais, fisioterapeutas, psicomotricistas e pedagogos, entre outros.

Destacava Brandão (apud STOBÄUS e MOSQUERA, 2006, p. 223):

O trabalho da estimulação precoce atua sobre o desenvolvimento da criança, visando auxiliar as modificações físicas e intelectuais do portador de necessidades especiais, por meio de intervenções adequadas desde os primeiro dias de seu nascimento. Seu objetivo principal está, entretanto, mais centrado na família e na relação desta com o recém-nascido, do que em técnicas de bombardeio sensorial, destinados, supostamente, a despertá-lo.

A Estimulação/Intervenção Precoce deve acontecer desde o nascimento e diagnóstico, dando início à Educação Infantil, entre os zero e três anos e onze meses, para todos com dificuldades de aprendizagem, que seja a mais produtiva possível, lembrando das denominadas janelas de oportunidade, em termos de desenvolvimento neurológico. Devem ser muito bem trabalhadas diversas formas de estimulação/intervenção, visando também conhecimento de si e de mundo, pois, no decorrer da trajetória dessa criança, além das limitações que ela traz consigo, são enfrentadas inúmeras barreiras que dificultam seu desenvolvimento psicossocial, e, uma delas é a inclusão numa escola, preferencialmente na Rede Regular de Ensino, conforme prevê a lei. 


\section{Inclusão educacional}

A discussão, num âmbito geral, em relação à inclusão, amplia-se ultimamente, sendo aspecto positivo tanto para a Educação quanto para inserção social. Independente do grupo social, cada pessoa tem diferentes opiniões, interesses e necessidades, entretanto é fundamental que aprendamos a conviver em diversidade.

A Constituição da República (BRASIL, 1988) em seu art. 208, inciso V, prevê o "acesso aos níveis mais elevados do ensino, da pesquisa e da criação artística, segundo a capacidade de cada um". Percebemos capacidades e ritmos diferenciados individuais, que precisam ser respeitados, não tratando-se somente de deficiência, mas também individualidades a serem entendidas/atendidas. A Declaração de Salamanca (BRASIL, 1994) também direciona para este entendimento/ atendimento.

Recordemos, entretanto, que leis não garantem tudo. Perguntaríamos: de que adiantam tantas leis quando não há recursos para superar simples barreiras arquitetônicas, atitudinais e sociais? Como propor uma nova forma de atendimento sem uma continuada qualificação profissional dos professores? Como atender específica e qualitativamente a criança especial levando em conta o número excessivo de alunos em uma sala de aula?

Recordamos Camacho (apud STOBÄUS e MOSQUERA, 2006, p. 11), quando afirmava que:

Assumir a diversidade supõe reconhecer o direito à diferença como enriquecimento educativo e social. Assumir a diversidade implica uma virada profunda nos modos convencionais de pensar e atuar, de fazer educação, política e reforma educativa.

Numa ótica escolar mais ampla, diversidade significa saber romper com esquemas tradicionais, para desenvolver o que realmente somos capazes de fazer, o que Vygotsky sempre disse: desenvolver a ZDP - Zona de Desenvolvimento Potencial. O importante é organizar situações de ensino, de tal forma que seja possível personalizar experiências de aprendizagem, isto é, conseguir o êxito de interação/participação de todos alunos, sem perder de vista necessidades individuais. Quanto mais flexível essa organização, mais fácil será a incorporação docente no apoio à dinâmica de sala de aula, facilitando o processo de aprendizagem discente. Quem sabe um dia também possamos considerar que pais têm muito a ensinar e aprender dentro da sala de aula (com seus filhos e os dos outros).

Porém, inclusão não restringe-se somente à sala de aula e à disponibilidade docente, também à preparação global (em termos de inclusividade) de quem atende (ou não) a criança e sua família, para efetiva inclusão em escola regular, processo que não se dá rapidamente, sendo necessário um acompanhamento, preparação e avaliação através de multiprofissionais especializados. 
As críticas, em relação às escolas especiais, seriam mais por serem vistas como uma forma de segregação ou por desconhecimento de seu trabalho, porém não podemos esquecer os benefícios dessa instituição, que busca um fazer pedagógico voltado para a construção da autonomia dos seus educandos, em um ambiente de socialização que respeita ritmo e tempo.

Essa organização escolar vai de encontro à idéia de inclusão, na qual o aluno incluído deve ter direito a adaptações curriculares quase que de forma individualizada, a uma avaliação diferenciada em que aspectos qualitativos sobreponham-se aos quantitativos, e o professor precisa saber identificar as necessidades especiais para implementar respostas educativas para estas necessidades, visando a atuação intencional e organizada nos processos de aprendizagem, com estratégias de flexibilização e práticas pedagógicas alternativas.

\section{A investigação}

Fernandes (2008) fez estudo de caso qualitativo, com entrevista à mãe e à professora de um aluno com Síndrome de Goldenhar, então com 6 anos e 7 meses, incluído na escola em que trabalha.

Da entrevista com a mãe, destacamos: "a gravidez foi ótima, [...] parto via cesária". Quando soube que algo não estava bem, referiu: "o mundo caiu sobre a minha cabeça, quando me trouxeram ele todo inchado, todo torto, a pele dele cheia de manchas, eu não toquei só dizia 'leva, leva, leva', [...], sem uma orelha, não tinha o globo em um olho e no olho bom faltava a janelinha, a testa era prá fora. Em seguida que ele nasceu ele teve uma convulsão".

Lembrando Kortmann, expectativas de ter um filho 'normal' podem não concretizar-se, e estresse e desconhecimento podem impedir até correto atendimento maternal inicial. Somente ficou mais tranqüila quando, "[...] internado na UTI 40 dias, [...] veio a geneticista, fez perguntas e pediu para reunir nossas famílias, para ver se achava algo, não achou nada e foi aí que ela fez o diagnóstico".

Conforme relatório médico, disponibilizado pela mãe, o menino nasceu de parto cesáreo na $39^{\mathrm{a}}$ semana de gestação, pesando $2755 \mathrm{~g}$, com $49 \mathrm{~cm}$ de comprimento e o perímetro cefálico de $36 \mathrm{~cm}$. O índice APGAR foi 8 no primeiro e no quinto minuto. Apresentou dificuldade para respirar logo após o nascimento, tendo sido utilizada ventilação mecânica por alguns dias. Foi avaliado por diversos especialistas: oftalmologistas, neurologistas, otorrinolaringologistas, fonoaudiólogos, cardiologistas, radiologistas e geneticistas. Nos exames realizados foram observadas as seguintes alterações:

- Olho esquerdo: cavidade anoftálmica, aparentemente sem a presença de cistos. 
- Olho direito: colboma da pálpebra superior direita: microftalmia com opacificação da córnea; presença de dermóide corneano; movimento de busca e reflexo orbicular presentes; pólo posterior preservado, sem alterações significativas.

- Nariz: ponte nasal alta; estenose da coana direita.

- Região oral: laringomalácia; presença de refluxo gastro-esofágico

- Orelha esquerda: presença de três apêndices pré-auriculares.

- Coração: discreto sopro sistólico secundário a leve estenose da art. pulmonar.

- Coluna: fosseta na região sacral; malformação vertebral ao nível da transição tóraco-lombar (provável fusão vertebral).

- Avaliação neurológica: diminuição dos reflexos e hipotonia.

- Tomografia computadorizada: sem malformações do sistema nervoso central.

Em relação ao desenvolvimento global do menino a mãe conta:

ainda na UTI ele fez cirurgia com oftalmologista para fechar a pálpebra. [...] dificuldade [...] quando foi para casa. Não tinha ninguém para ajudar, era eu sozinha para tudo e a minha cabeça não ajudava, era que nem um novelo de linha, não entendia nada. Na primeira semana eram 7 médicos, 4, 5 médicos por semana, fora os atendimentos, sendo que a gente não sabia onde procurar os atendimentos, não sabia nada, saí procurando particular, procurei terapeuta ocupacional e a fonaoudióloga, de cara, o fisioterapeuta foi mais tarde, porque tinha que aprender a sugar.

Relatou:

o ofalmologista disse que de $15 \mathrm{em} 15$ dias, teria que ir no consultório particular dele, ele botou um silicone onde não tem o globo, depois passamos a ir de mês em mês e após dois anos ele colocou um balonete. Esse balonete tem uma válvula por debaixo da pele, e de três em três meses o médico coloca $1 \mathrm{ml}$ de soro fisiológico para o balonete crescer de tamanho, hoje ele tem 13 $\mathrm{ml}$ e meio de soro fisiológico. Então o oftalmologista falou que parece que ele vai parar de colocar soro fisiológico porque o balonete já tá de bom tamanho. Esse médico pede todos os anos [...] tomografia para ver o desenvolvimento do globo, do buraco do olho, para ver como é o tamanho, que está bom, que está se desenvolvendo bem, porque ele tem que acompanhar o outro olho. Agora a gente talvez vai colocar a órtese, para estética. 
Quanto ao quadro ósteo-articular e neurológico disse:

fez a cirurgia da coluna com 3 anos e 2 meses, foi retirado um pedaço da minha bacia, daí nós dois entramos na sala de cirurgia, a coluna tem um acompanhamento até os 18 anos. De 6 em 6 meses, a gente tira um raio $\mathrm{x}$, ele tem um acompanhamento bom, está dando tudo certo. Na parte neurológica há ressonâncias do crânio de 2 em 2 anos, os encefalogramas, também de 2 em 2 anos.

Caminhou por volta dos 3 anos. A terapeuta ocupacional usou um método para caminhar, porque os pais viam que não caminhava por insegurança, como ele enxergava pouco e tinha desequilíbrio do lado direito e mais a visão, destacando a mãe que "eu sentia que ele não tinha segurança, daí em casa eu pegava um pano, estimulava muito em casa". Com 3 anos e 9 meses fez a primeira cirurgia do pé, com 4 anos e 5 meses fizemos nova cirurgia, agora anda bem melhor, após fisioterapia. Boa equipe multiprofissional, intervindo precocemente, ocasiona excelentes resultados.

Em março de 2006, entrou na pré-escola, “[...], daí me disseram que não levasse mais mamadeira mas caneca, colocava caneca mas também a mamadeira na mochila, quando saía da escola sentava na calçada e dava água na mamadeira escondida da professora".

Como a Síndrome atinge mais ossos da face, em especial ao redor dos olhos e ouvidos, nos primeiros meses o médico mandou para fonoaudióloga realizar o exame audiológico (Teste Bera), já realizou 9 vezes. Identificaram que, apesar de que "escuta tudo, sabe o som do carro, do portão", aos três anos colocou aparelho auditivo, óculos, 'aparelho' no céu da boca que estava cada vez mais côncavo, logo a seguir realizou uma cirurgia.
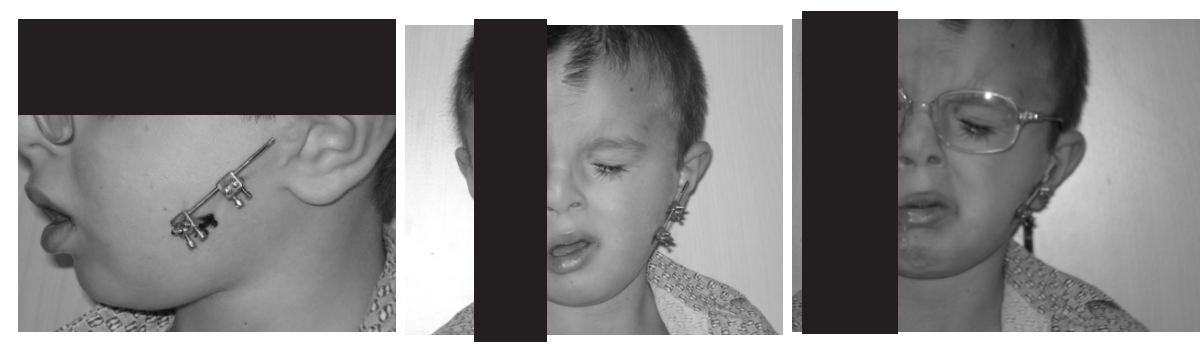

Fonte: fotos da criança, após a cirurgia, com expansor de mandíbula.

Mais especificamente, sobre dificuldades na inclusão escolar, a mãe relata que:

A escola foi muito importante, pelo convívio com as crianças. Com cinco anos, após dois anos em que ele ficou na escolinha, aprendeu a tomar água sozinho, começou a ir ao banheiro sozinho, conhecia todos os números e a maioria das letras, escrevia o nome, estava bem mais interessado: se está no ônibus ou em 
qualquer lugar, com a placa do carro ou um lugar qualquer, em determinada palavra, demonstrado quando aponta com o dedinho sobre elas, quando pede por exemplo água, diz 'A', para mamãe é 'mama-mama', pega pela mão e leva a pessoa, fala A, E, I, O, U e a palavra 'Oi', faz sinais de tudo bom, de tchau.

que:

Ao ser questionada sobre como aconteceu a socialização via escola, relatou

que:

Quanto às outras crianças, o mais difícil é estar num lugar que tem mais crianças, por exemplo num parque ou num hospital, já que ele vai muito ao hospital, uma criança pára para olhar, então todas elas param para ver o olho dele, a primeira coisa que as crianças olham já vêem que ele não tem um olhinho, daí já ficam um pouco assustadas.

Quanto ao relacionamento do filho na escola, com as outras crianças, refere

Ele é 'normal', porque acho que ele não sabe ainda que não tem um olhinho, quando as crianças dão uma parada e o P. quer abraçar todas elas, umas deixam e outras fogem. Então, as crianças' normais' meio que se assustam, mas como eu já tô acostumada, levo normal. No início já me doía um pouco a diferença de quando ele está na escolinha, pois as crianças 'especiais' aceitam, uma olha para outra e aceita o 'normal', não tem essa diferença de olhar.

Ao refletir sobre essa resposta da mãe, podemos perceber a necessidade deste 'novo olhar para a diversidade e grandes deficiências', que temos enquanto sociedade, em relação ao outro diferente de nós, justamente por não entendê-lo, mais pelo próprio desconhecimento do diverso/diferente, do que de pré-conceitos/preconceitos. Já, mais especificamente sobre como vê suas dificuldades na escola, esclarece que:

Nos primeiros dois meses, ele chorava um pouco, mas depois ele queria vir para a escolinha, ele gosta de lá. Então, quando eu ia botar o uniforme, de manhã, eu falava o nome da escolinha e ele já pulava rápido e já botava rindo, o nome da escolinha chama muito a atenção.

Após toda essa trajetória e suas conquistas pessoais e familiares, recebeu a indicação para passar a frequentar a Rede Regular de Ensino. Sobre essa transposição da Escola Especial para a Rede Regular, antes da correção da mandíbula, respondeu:

Em outubro de 2007, a professora disse que tínhamos que procurar uma [...] pré-escola numa escola regular. Comecei a procurar escolas, [...]. Então parti para colégios particulares, procurando. Fui em vários colégios e onde ele foi muito bem aceito foi na ACM. A gente chegou lá, passou pela psicóloga, e por ela já estava feita a matrícula naquele dia mesmo. Os alunos estavam 
em aula, depois estavam no lanche, ele adorou tudo, adorou o pátio, as crianças brincando e ele já se entrosou junto. Então, até hoje na ACM estão esperando ele, a vaga dele está lá. Nós fomos lá, conversamos, mas o meu esposo não quer fazer a matrícula sem ter certeza se ele pode começar o ano em março, porque, como ele vai fazer a cirurgia da mandíbula e acho que os parafusos vão ficar para o lado de fora e ele não pode cair, nós temos que saber quantos meses ele tem que ficar sob cuidados para depois fazer a matrícula.

Durante entrevista com a professora da Escola Especial, descobrimos que durante estes dois anos, recebeu os estímulos que permitiram a superação de barreiras, que fizeram com que ele, hoje, tenha melhores condições de freqüentar uma sala de aula na rede regular de ensino:

Chegou na escola bem dependente, na hora do lanche ele queria tudo nas mãos, tudo na boca, chorava muito, usava fraldas, não interagia com os colegas e a gente começou a perceber que o problema dele se estendia era uma questão familiar. A mãe dele era uma pessoa extremamente insegura, não acreditava no potencial e nas habilidades do filho, fazia tudo por ele, questão de superproteção, ele não podia fazer as coisas sozinho porque podia se machucar ou não ia conseguir. A gente começou a trabalhar isso com ela também, que ele tinha capacidade, que ele tinha potencialidades e ela começou acreditar no trabalho da gente na escola, no trabalho da instituição, e a criança passou a se sentir segura também porque a mãe estava mais segura, e começou a responder a todo o trabalho que era feito aqui.

Ao final, era criança mais independente, identificava seu material e o dos colegas, na hora do lanche organizava seu material, já comia sozinho, largou as fraldas, pedia para ir ao banheiro, já falava e reconhecia todas as vogais, estava passando para o restante do alfabeto, interagia com os colegas e compartilhava seu o material, buscava os objetos que ele queria, mas ainda tinha certa resistência ao novo.

Lembremos aqui estar diante de atividades de vida diária, tão necessárias de serem enfrentadas e superadas nestes anos iniciais, para alavancar socialização/ educação, inclusive formal.

Relata a professora:

É uma criança bem metódica, tem a rotina aqui na escola, segue essa rotina e quando a gente oferece algo novo ele se desorganiza um pouco, mas isso é questão de que é uma criança sistemática, isso é uma coisa bem natural, que até a gente é assim, então a adaptação dele foi na verdade uma descoberta. Aflorou, ele era uma criança introvertida em função de toda a questão familiar, foi uma criança que nasceu e a mãe já tinha uma certa idade, não esperava. Nasceu com problema, então toda aquela expectativa foi um pouco frustrada e a mãe até comentou isso 
por vezes comigo, então tem toda aquela superproteção, filho único, especial, e a gente começou a mostrar o que podia ser trabalhado com essa criança de uma forma mais tranqüila, que é uma criança super esperta, apesar de toda a patologia dele, tem o cognitivo super bom, pois já está quase se alfabetizando e isso mostra que o cognitivo dele está em perfeitas condições tanto é que, ele esta indo para a escola regular porque foi detectado que ele já passou por todas as fases que ele podia passar aqui na pré-escola. Então, ele tem que ser ingressado numa escola regular, não precisa mais fazer parte da escola especial porque é uma criança que tem que voar mais alto e a patologia dele já diz que a parte física é bastante comprometida mas o cognitivo é positivo, então a gente aproveitou essa questão do cognitivo preservado e agora ele está pronto para ir para uma escola regular. A mãe já está mais tranqüila, já aceitou, acredita agora no filho dela e a gente ta acreditando que o trabalho vai dar certo.

Revendo este último comentário docente, vemos o quanto 'acreditavam no potencial', passando também estes 'momentos' para seus pais, que souberam entendê -la. Com relação aos colegas, relatou que essa socialização já havia extrapolado a sala de aula, que, quando saía, comunica-se com os outros e abraçava-os, que sua família e a socialização na escolinha efetivamente causaram este desenvolvimento.

\section{Comentários finais}

Ao considerar as manifestações descritas, lembremos que é necessário que os profissionais que atuem com essas crianças utilizem técnicas e recursos diferenciados que estimulem a expressão, linguagem, motricidade, socialização realização de atividades da vida diária bem como, o desenvolvimento biopsicosocial. Dentre os achados mais significativos, ressaltaríamos aspectos clínicos: ocorre mais em meninos; malformação visual, auditiva e ósteo-muscular, que devem ser detectadas e corrigidas precocemente, para melhor socialização e inserção escolar, através de apoios de uma equipe multiprofissional bem preparada.

As entrevistas esclareceram dificuldades familiares, superando expectativas/pré-concepções 'não realizadas', 'enfrentamentos e superações' de situações, direcionando para maiores conhecimentos, aceitação e superação de adversidades, 'educando-se' nessas novas situações. Na escola, da mesma forma, lembremos a professora bem preparada e apoiada em suas ações, tanto pela escola como pela família, destacando-se a necessidade de conhecer para poder melhor atender. Os colegas de turma, muitas vezes, aceitam mais facilmente, interagindo com mais celeridade que os próprios pais/docentes. Apoio familiar é importantíssimo.

Auxiliar a família, com informações melhores encaminhadas, mais corretas e coerentes com a realidade vivenciada, pode ser possível através dessas entrevistas. Destacamos que, mesmo sendo difícil a superação do 'luto', que surge com a chegada de um filho 'diferente do esperado', deve-se sempre levar a família a sentir-se, cedo, como a principal referência e incentivo para que haja efetiva inclusão num âmbito inicialmente familiar, com suporte de segurança, afeto, e mais adiante, possibilitando a 
inclusão educacional, para que a mais ampla, a inclusão social, possa, posteriormente, realmente acontecer. Este caso ilustra que a inclusão em uma escola regular é possível, porém requer elementos essenciais, entre eles: a aceitação da família, o acompanhamento de vários profissionais especializados trabalhando coordenadamente e a disponibilidade da escola atender a diversidade, com docentes bem preparados.

\section{Referências}

BRASIL. Declaração de Salamanca. Brasília, CORDE, 1994.

Lei de Diretrizes e Bases da Educação Brasileira 9394/96. Brasília: MEC, 1996.

FERNANDES, C. R. C. Síndrome de Goldenhar. Monografia (Especialização em Educação Inclusiva) Faculdade de Educação da PUCRS, Porto Alegre, 2008.

MOCELIN, M.; CAPASSO, R.; CATAM, G. S. A.; GASPERIN, A. C.; JUNIOR, A. O. W. Sindrome de Goldenhar (Displasia Oculoaurículovertebial). Relato de Caso e Revisão de Literatura. Disp. em 〈http://www. rborl.org.br/conteudo/acervo/print_acervo.asp?id?=2561>. Acesso em: 26 jan 2008.

PINTO, F. T.; ARAÚJO, C. B.; SOUSA, E. C.; CHIARI, B. M. Alterações fonoaudiológicas presentes em um caso de Síndrome de Goldenhar. Disponível em: 〈http://www.scielo.br/pdf/rsbf/vl2n2/10.pdf〉. Acesso em: 10 jan. 2008 .

PINTO, N. F.; FIGUEIREDO, M. C.; GUARIENTI, C. A. D. Relato de caso clínico - Síndrome de Goldenhar. Disponível em 〈http://www.uepg.br/propesp/publicatio/bio/2004_3-4/03.pdf〉. Acesso em: 26 jan. 2008.

SANVITO. W. L. Síndromes Neurológicas. 2. ed. São Paulo: Atheneu, 1997.

SMITH, D. W. Síndromes de malformações congênitas. Aspectos genéticos, embriológicos e clínicos. 3. Ed. São Paulo: Manole, 1989.

STOBÄUS, C. D.; MOSQUERA, J. J. M. Educação Especial: em direção à Educação Inclusiva. 3. ed. Porto Alegre: EDIPUCRS, 2006.

\section{Correspondência}

Claus Dieter Stobäus - Pontifícia Universidade Católica do Rio Grande do Sul. Av. Ipiranga, 6681 - Partenon, CEP: 90619-900, Porto Alegre, Rio Grande do Sul, Brasil.

E-mail: stobaus@pucrs.br

Recebido em 25 de outubro de 2012

Aprovado em 31 de março de 2013 